\title{
A numerical study of harmful gas dispersion based on CALPUFF model
}

\author{
Yanyan $\mathrm{Lu}^{1, *}$ \\ ${ }^{1}$ Atmosphere \& Remote Sensing Department, Nanjing University of Information Science \& Technology Binjiang College, Nanjing, \\ 210044, P. R. China.
}

\begin{abstract}
Severe gas leakage accidents occasionally happened during the exploitation of high-sulfur gas, the consequent harmful gas dispersion could seriously impact the air quality, cause large-scale casualties and economic losses. Therefore, people's comprehensive understanding of harmful gas dispersion in both spatial and temporal dimensions should be improved. This paper takes gas well blowout accident in Kai County, China, as the case study, simulates and analyzes the dispersion characteristics of the leaked gas, mainly focuses on $\mathrm{H}_{2} \mathrm{~S}$. The CALPUFF model is applied to execute the experiment, the detailed meteorological data, complex terrain data, wet deposition and chemical transformations are all under consideration. The result shows that due to different impact factors, such as complex terrain and gas density variations, $\mathrm{H}_{2} \mathrm{~S}$ exposure risk was higher in the valley area than that on the mountain, which also explains why Xiaoyang and Gaowang villages have a great number of casualties. Besides, the analysis result is basically consistent with the historical local news and reported data, which demonstrated that our case study of $\mathrm{H}_{2} \mathrm{~S}$ gas dispersion simulation is reasonable and reliable.
\end{abstract}

\section{Introduction}

With the rapid development of urban industrialization all over the world, the consumption of resources is gradually increasing. The air pollution problem and even the emergency response system has drawn great attention both in the industrial and academic areas. Drilling, oil fields and chemical plants are some areas which should be given particular attention, because these areas are easily to cause toxic and harmful gas leakage accidents due to various impacts. The consequent result of the harmful gas dispersion could seriously impact the air quality, people's health and even economic losses [12]. Therefore, it is of great significance to control air pollution and simulate the range of pollutant diffusion. Mastering the physical mechanism and characteristics of the airflow and harmful gas diffusion regularity, and accurately predicting the pollution result spatiotemporally in the surrounding areas around the source of the accident, can be essential guidelines to ensure safety production, and also the basis of accident risk assessment, emergency planning and alarm mechanism.

Therefore, a great number of researchers have investigated atmospheric diffusion simulation based on computational fluid dynamics (CFD) method, CALPUFF model, AERMOD model and etc. For instance, Z.H. Lian, J.G. Chen and R.G. Du explored the natural gas leakage in Kai country using a computational fluid dynamics method based on Fluent software respectively [3-5]. D.X. Yang and M. Li studied the same problem based on the widely used Atmospheric Regulatory model, namely CALPUFF model, which achieved a reasonably good result compared with the real situation [6-7]. The CALPUFF model is also used to investigate air pollution simulation in some regional areas due to its excellent performance [8-10]. Indian researchers have used this model to study the diffusion of pollutants above the land-water interface. American researchers have used this model to calculate the sedimentation values of cadmium, zinc and lead. CALPUFF model has also been used by Italian researchers to evaluate the olfactory damage caused by odor from municipal solid waste anaerobic treatment plants [11-13].

However, the current research lacks of comprehensive analysis for spatio-temporal characteristics of gas diffusion procedure, and an efficient way to directly observe and analysis the spatiotemporal procedure of gas leakage and dispersion, and some essential problems still need to be investigated and improved. This paper explored the gas well blowout problem based on CALPUFF model, considering both the meteorological data and complex terrain data, and analyzed the peak value varied with time, which could help people comprehensively understand the $\mathrm{H}_{2} \mathrm{~S}$ gas dispersion regularity.

\section{CALPUFF model setup and configuration}

The CALPUFF model is a regulatory guideline model developed by the US Sigma Company under the long-

Corresponding author: LuYanyanella@163.com 
term support of the US EPA. It is one of the recommended atmospheric diffusion simulation models in China, which is mainly used in post-mortem risk assessment, fault analysis, air quality testing and emergency response. The CALPUFF model considers the effects of complex terrain and slope on the wind field, combines the data of meteorological conditions, topography, surface, pollution source location and physical settlement mechanism of the study area. The atmospheric diffusion process that changes randomly with time and space can be stimulated through numerical methods, and the result of pollution concentration can be predicted hourly, monthly, and yearly. The CALPUFF model system mainly includes four modules: the preprocess module, the meteorological model CALMET, the diffusion model CALPUFF and the post-processing module CALPOST. The procedure is shown in Fig. 1.

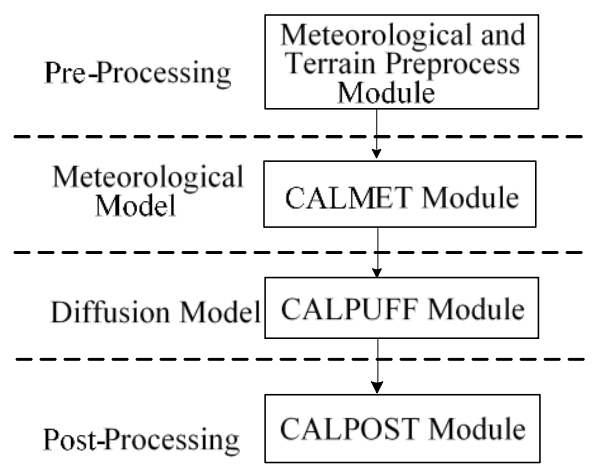

Fig. 1. Four modules of the CALPUFF model system.

Where the meteorological model CALMET includes diagnostic wind field generators and a micrometeorological model. According to the special format of meteorological data and geographical data, the temperature field of three-dimensional meteorological field with time variation and the related geographical field are generated. The diffusion model CALPUFF is an unsteady Lagrangian smoke cluster model, which simulates the meteorological conditions that change with time and space by superimposing the data of the meteorological field and related pollution sources generated by CALMET, wet and dry deposition of pollutants, and chemical conversion. The CALPOST post process is to post-process the results of the CALPUFF model and output the hourly, daily and monthly average concentration files.

Specifically, the CALPUFF model describes continuous plume dispersion using a set number of discrete packets of contaminants, and typically use snapshots to assess the concentration contribution of a single puff to a receptor. It provides two snapshot sampling functions, the first using a radial symmetric Gauss puff and the second using a non-circular puff. Both methods are based on the MESOPUFF model, which are described as follows.

\subsection{Integral smoke cluster sampling function equation}

The basic equation for the concentration contribution of a single puff at a receptor point is:

$$
\begin{gathered}
C=\frac{Q}{2 \pi \sigma_{x} \sigma_{y}} g \exp \left[-d_{a}^{2} /\left(2 \sigma_{x}^{2}\right)\right] \exp \left[-d_{c}^{2} /\left(2 \sigma_{y}^{2}\right)\right] \\
g=\frac{2}{(2 \pi)^{1 / 2} \sigma_{z}} \sum_{n=-\infty}^{\infty} \exp \left[-\left(H_{e}+2 n h\right)^{2} /\left(2 \sigma_{z}^{2}\right)\right]
\end{gathered}
$$

Where $C$ is the concentration of ground pollutants at the receptor site $\left(\mathrm{g} / \mathrm{m}^{3}\right), Q$ is the quality of the contaminants in the puff $(g), \sigma_{x}$ is the standard deviation of Gaussian distribution of contaminants in $\mathrm{X}$ direction (horizontal wind direction)(m), $\sigma_{y}$ is the standard deviation of Gaussian distribution of pollutant in $\mathrm{Y}$ direction (vertical horizontal wind direction)(m), $\sigma_{z}$ is the standard deviation of Gaussian distribution of pollutant in $\mathrm{Z}$ direction (Vertical Direction) $(\mathrm{m}), d_{a}$ is the distance from the center of the puff to the receptor point in the $\mathrm{X}$ direction $(\mathrm{m}), d_{c}$ is the distance from the center of the puff to the receptor point in the $Y$ direction(m), $g$ is the vertical term of Gauss equation(m), $H_{e}$ is the effective Height from the center of a puff to the ground(m), $h$ is the mixed layer height(m).

\subsection{Calculation and sampling function of smoke slice}

The smoke sheet can be regarded as a set of overlapping but very small spacing smoke clusters, describing the continuous emission of smoke clusters. The length of the main body of the cigarette is $u \Delta t_{\mathrm{e}}, u$ is the wind speed, $\Delta t_{\mathrm{e}}$ is the time of emission of pollutants. The concentration of a smoke sheet can be described as:

$$
\begin{gathered}
C(t)=\frac{F q}{(2 \pi)^{1 / 2} u \sigma_{y}} g \exp \left(\frac{-d_{c}^{2}}{2 \sigma_{y}^{2}} \frac{u^{2}}{u^{2}}\right) \\
F=\frac{1}{2}\left[\operatorname{erf}\left(\frac{d_{a 2}}{\sqrt{2} \sigma_{y 2}}\right)-\operatorname{erf}\left(\frac{-d_{a 1}}{\sqrt{2} \sigma_{y 1}}\right)\right]
\end{gathered}
$$

Where $u^{\prime}$ is the average wind vector $(\mathrm{m} / \mathrm{s}), u^{\prime}$ is the wind scalar $(\mathrm{m} / \mathrm{s})$, which is defined as:

$$
u^{\prime}=\sqrt{u^{2}+\sigma_{V}^{2}}
$$

$\sigma_{\mathrm{v}}$ is the variance of the wind speed, $q$ is the source emission $\operatorname{rate}(\mathrm{g} / \mathrm{s}), F$ is the causality function, which solves the edge effect of smoke slice end attachment, $d_{\mathrm{c}}$ is the distance from the smoke slice to the receptor along the direction perpendicular to the axis of the smoke slice $(\mathrm{m}), d_{\mathrm{a} 1}$ is the distance from the first end of the smoke slice to the receptor along the axis of the smoke slice $(\mathrm{m}), d_{\mathrm{a} 2}$ is the distance from the second end of the smoke slice to the receptor along the axis of the smoke slice $(m)$.

\section{Data Processing}




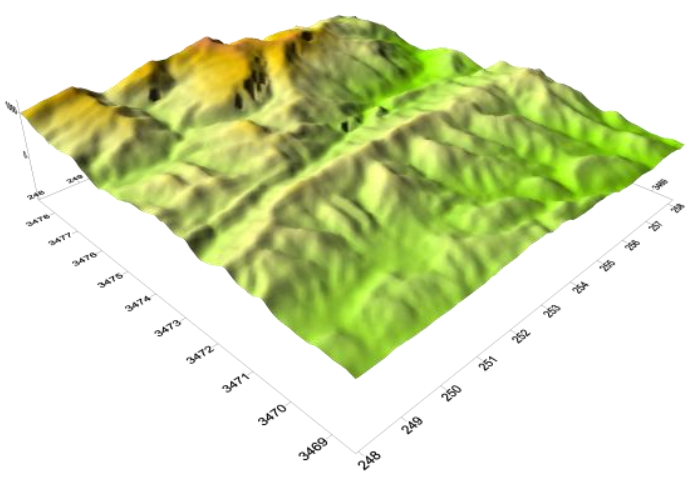

(a) Terrain data of the study area.

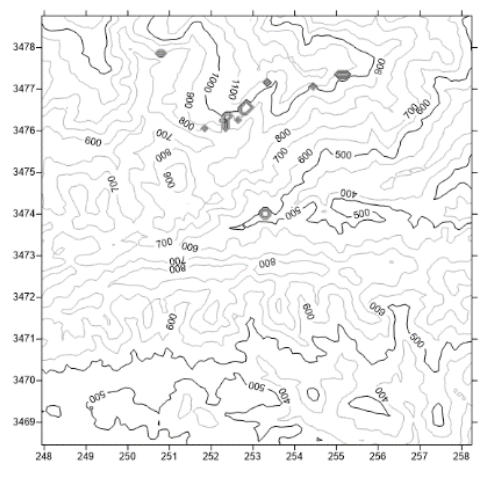

(b) Topographic contour.

Fig. 2. Terrain data of the study area.

This study focuses on the sour gas well blowout accident, which occurred in Kai County on December 23, 2003 at 22:00 local time, located in the southwest of China. According to the statistically data, there was approximately 243 deaths and 64,000 people were evacuated from the accidental area. The UTM coordinate of pollution source center is $(237.321 \mathrm{~km}, 3474.793 \mathrm{~km})$, with UTM time zone 49 , WGS-84 coordination. The terrain data of the study area and its topographic contour plot are shown in Fig. 2.

The terrain data, land use data and the meteorological data are processed by CALMET module. where the meteorological grid spacing is $0.1 \mathrm{~km}$ and the grid number is set to $104 \times 104$. On the day of the accident, the wind direction was northwest and the wind speed was about $1 \mathrm{~m} / \mathrm{s}$. In the CALPUFF model, the plume segmentation was performed using a smoke cluster model, the Briggs plume ascent model and the ISCST atmospheric diffusion model were used, and also the PG coefficient was applied. Other parameters used in this case study is shown in Table 1.

Table 1. The values of other parameters

\begin{tabular}{|c|c|}
\hline Parameter & Value \\
\hline Point source coordinates & $(237.321,3474.793)$ \\
\hline Exit velocity $(\mathrm{m} / \mathrm{s})$ & 40 \\
\hline Emission rate $(\mathrm{g} / \mathrm{s})$ & 6076.39 \\
\hline Stack height $(\mathrm{m})$ & 1 \\
\hline Diffusion time (min) & 120 \\
\hline The time step (s) & 0.01 \\
\hline
\end{tabular}

\section{Result and Analysis}

Based on the previous model configuration and data processing, the spatio-temporal characteristics of gas concentration at different time points are obtained.

As can be seen in Fig. 3, it shows the distribution of $\mathrm{H}_{2} \mathrm{~S}$ concentration on the ground every 10 minutes, 15 minutes, 30 minutes, 1 hour, 2 hours from the beginning of the blowout. The result shows that after the blowout, $\mathrm{H}_{2} \mathrm{~S}$ gas diffused rapidly within 10 minutes and spread to downwind direction around the surrounding villages, which is relatively consistent with the real situation. As the local news reported that people in Xiaoyang and Gaowang village smelt the odor gas after less than 10 minutes when they heard a loud boom of gas well blowout. It can be seen from the 15 minutes distribution in Fig. 3. that the $\mathrm{H}_{2} \mathrm{~S}$ gas diffusion does not appear as a circular or elliptical distribution on ordinary terrain, but instead moves along the valley or climbs up the mountain, and covered the Xiaoyang and Gaowang village. This is due to the fact that the density of $\mathrm{H}_{2} \mathrm{~S}$ is larger compared with the density of air and the complex terrain around this area, so the $\mathrm{H}_{2} \mathrm{~S}$ gas was heaver and most of the gas spread along the valley and little spread along the slope of the mountain. And also, there was a highland in the northeast direction of the blowout location, and Xiaoyang and Gaowang village are all located in the valley. As time passed, $\mathrm{H}_{2} \mathrm{~S}$ gas spread along and gathered in the valley area, this could explain why the casualty in these two villages accounted for $80 \%$ to $90 \%$ of the total deaths. The distribution of 1 hour in Fig. 3. shows that due to the influence of indirect westerly wind and northerly wind, $\mathrm{H}_{2} \mathrm{~S}$ gas continues to diffuse to the southeast. The 2 hours distribution figure indicates that the concentration slightly decreased compared to 1 hour, and $\mathrm{H} 2 \mathrm{~S}$ gas continued to accumulate in the low-lying areas along the valley to the southeast. This is because the mountain peaked on both sides of the valley prevented the spread of pollutants. Also, cold air slid down the hillside at night, it gathered at the bottom of the valley, causing radiation inversion temperature in the valley area at night. And because the valley wind speed was very small, making the thickening of the stratum was not conducive to the diffusion of pollutants. People should be guided to evacuate to high places to avoid poisoning.

Besides, we also investigated the peak value of $\mathrm{H}_{2} \mathrm{~S}$ concentration within 2 hours, as presented in Fig. 4. The $\mathrm{H}_{2} \mathrm{~S}$ concentration first rises significantly in $10 \mathrm{~min}$ to about $125 \mathrm{mg} / \mathrm{m}^{3}$, and maintains at the peak level for approximately $50 \mathrm{~min}$. After 1 hour, the figure drops 
gradually to about $20 \mathrm{mg} / \mathrm{m}^{3}$ and keeps at a low level. The simulated result is consistent with the reported data

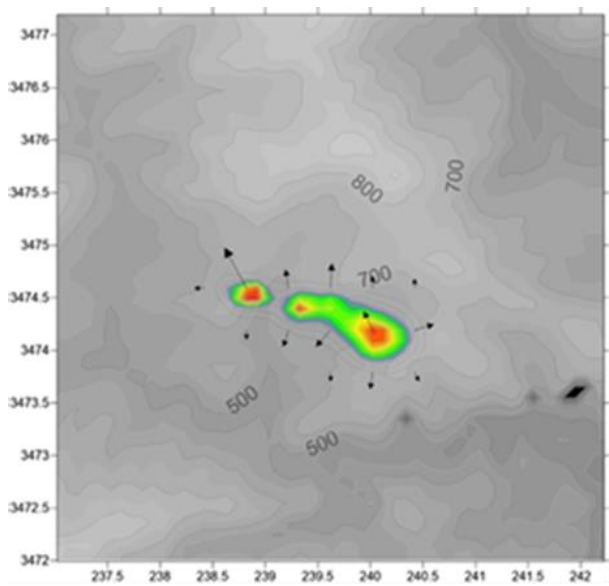

(a) $10 \mathrm{~min}$

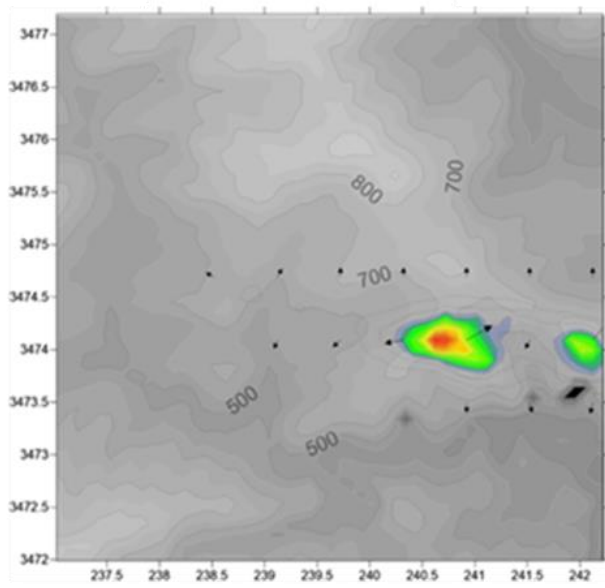

(c) $30 \mathrm{~min}$ and former studies, which demonstrated that our simulation and experiment is reliable and accurate.

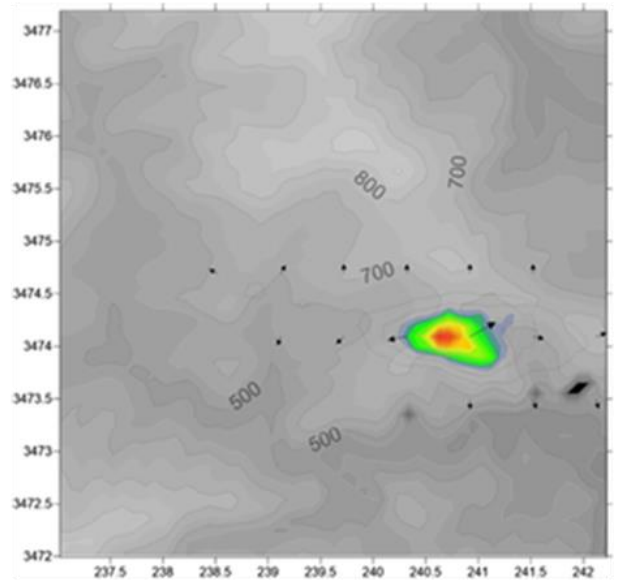

(b) $15 \mathrm{~min}$

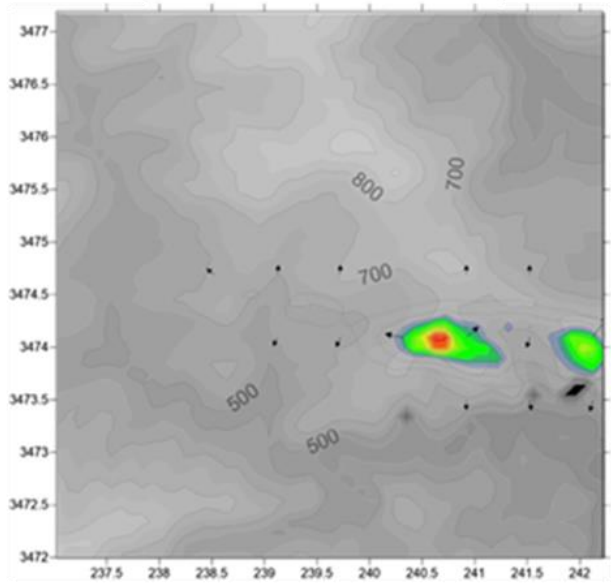

(d) $1 \mathrm{~h}$

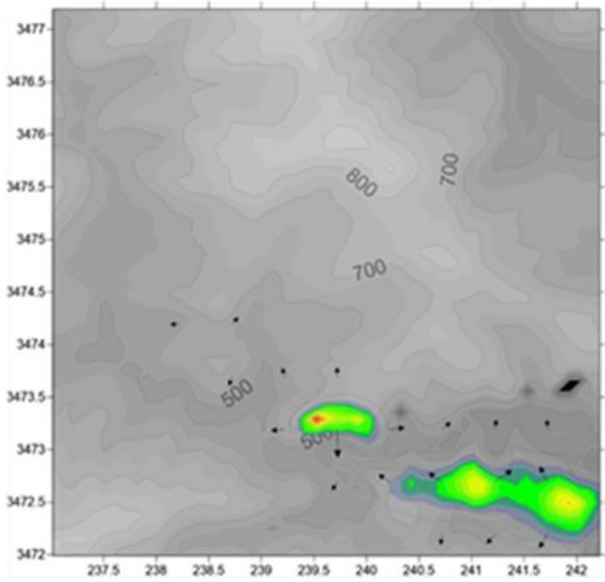

(e) $2 \mathrm{~h}$

$\mathrm{H}_{2} \mathrm{~S}$ mass fraction

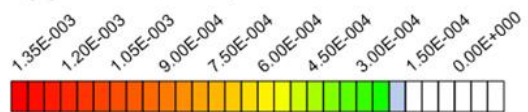

Fig. 3. Distribution of $\mathrm{H}_{2} \mathrm{~S}$ concentration near the ground at each time. 


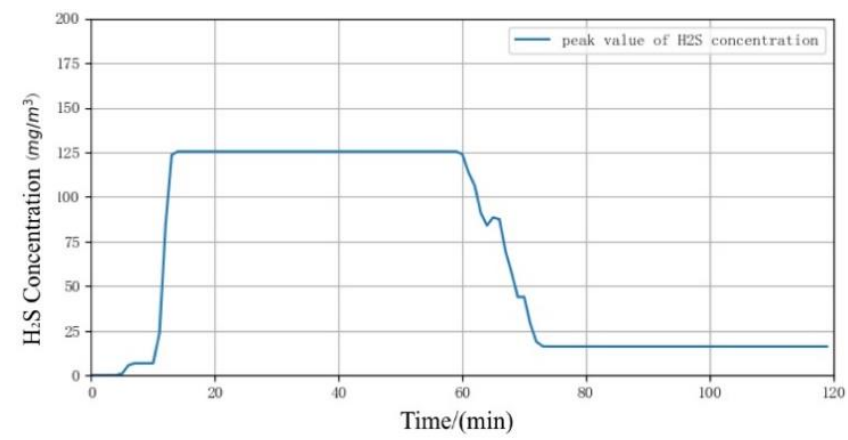

Fig. 4. Peak value of $\mathrm{H}_{2} \mathrm{~S}$ concentration near the ground

\section{Conclusion}

Generally speaking, the distribution of horizontal wind field and the stability of atmospheric stratification will affect the distribution characteristics of pollutants. On the winter day of the blowout, the wind speed was $1 \mathrm{~m} / \mathrm{s}$, and the atmospheric stratum was relatively stable, which was not conducive to the diffusion of gas. The gas diffusion was slow, the concentration was large and the range was small. According to the investigation of the accident, the pipe mouth of the Luojia well $16 \mathrm{H}$ was located on the slope of the mountain canyon terrain, at a high position on the hillside. $\mathrm{H}_{2} \mathrm{~S}$ gas concentration was significantly affected by the mountain canyon effect. The simulation result agrees well with the actual report and data. Here, three conclusions are summarized based on our study:

(1) Based on the meteorological data and real terrain data of the accident, CALPUFF model can accurately simulate the dispersion path and range of $\mathrm{H}_{2} \mathrm{~S}$ gas concentration spatio-temporally. The result shows that due to different gas density and complex terrain, the $\mathrm{H}_{2} \mathrm{~S}$ exposure risk was higher in the valley area than that on the mountain.

(2) Based on the simulation experiment, the spatiotemporal characteristics and evolution of $\mathrm{H}_{2} \mathrm{~S}$ gas concentration can be intuitively observed, which can be a reliable guideline for emergency response.

(3) The $\mathrm{H}_{2} \mathrm{~S}$ gas disperses slowly under the special static wind conditions at the accident time, and the effect range was mainly focused around two villages. A largescale natural gas explosion cloud was not formed, which is basically consistent with the result of the blowout accident investigation. The result proves that our case study of $\mathrm{H}_{2} \mathrm{~S}$ gas dispersion simulation is reasonable and reliable.

\section{References}

1. Y.Q. Xu, Qingdao University of Technology (2010)

2. Z.X. Yang, C.L. Duan, J.J. Zhang, GZ. Chem. Ind. 46,22(2018)

3. R.G. Du, B. Qi, H.H. Guo, Meteor. Hydro. Mar. Instrum. 14(2007)

4. Z.H. Lian, Z.M. Zhao, H. Wang, X.J. Li, T.J. Lin, Nat. Gas Ind. 29,112(2009)

5. J.G. Chen, S.M. Pan, Y. Liu, H.Y. Yuan, J. THU. (Sci. Technol.) 381(2007)

6. D.X. Yang, G.C. Chen, AAQR. 6, 430(2006)

7. M. Li, H. Liu, C.W. Yang, ISPRS Ann. Photogram. Remote Sens. 2(2015).

8. X. Bo, Z.X. Wu, G. Wang, Environ. Sci. Technol. 37,530(2014)

9. X.D. Zou, H.B. Yang, Y.C. Liu, J. Meteor. Environ. 24,24(2008)

10. Q.Y. Wu, J.Y. Huang, L. Sheng, J. Geo. Info. Sci. 17,206(2015)

11. S. Indumati, R.B. Oza, Y.S. Mayya, et al. Atmos. Environ.42,473(2009)

12. D.L. MacIntosh, J.H. Stewart, T.A. Myatt, et al. Atmos. Environ.44,262(2010)

13. L. Ranzato, A. Barausse, A. Mantovani, et al. Atmos.57,233(2013) 